\title{
ANTECEDENT FACTORS AFFECTING EMPLOYEES' TURNOVER INTENTION: A CASE STUDY OF INDOVINA BANK
}

\author{
by Nguyen Minh Kieu ${ }^{1}$ - Tran Chi Hong ${ }^{2}$
}

\begin{abstract}
Employee turnover has become a great concern and sleepless night of human resource managers. Recently, many researches had been conducted to answer the question why employees wish to change their jobs. The majority of these studies are trying to find out what are the factors affecting their decisions. These kinds of studies are tapping at the behavioral aspect of turnover. However, in banking sector, there have not been many studies on the attitudinal aspect of turnover. This is a gap in studying on employee turnover. The purpose of this study is to fill the gap and answer the question under the approach on the attitudinal side. This kind of view on turnover is originated by the idea that beliefs and attitude have an extent of guidance on behavior intention and actual behavior. If we can change their attitude and limit their behavioral intention, the chance of their actual turnover behavior shall be reduced.
\end{abstract}

Keywords: turnover intention, employee turnover, affective commitment, continuance commitment, job satisfaction.

\section{INTRODUCTION}

The objectives of this research are to identify the factors that affect the turnover intention of Indovina Bank's employees and to determine the important level of these factors. Based on findings, the research will assist the Management of Indovina Bank to have a better view and understanding on human resource, thus to have a proper improvement on their human resource practices and better solutions for their staff retention policy.

In term of research methods, this research is a combination of qualitative and quantitative research. In the exploratory stage, qualitative approach was used to identify the factors that could have association with the turnover intention. Data is collected through the in-depth interviews with predetermined and structured questions. In the formal stage, this research uses quantitative approach to test the hypothesis of the impact of these factors on turnover intention.

The rest of this paper is organized as follows: Part 2 provides a literature review and research model. Part 3 presents a research methodology. Part 4 gives a data analysis and research findings. The final part isare conclusions and recommendations. Should have a paper structure here

\section{LITERATURE REVIEW AND RESEARCH MODEL}

In a human resource context, turnover or labor turnover is the rate at which an employer gains and looses his or her employees. Turnover is considered as dysfunctional to organizations. Industrial psychology literature treats it as an element of job-withdrawal related to job tenure, absenteeism and tardiness (Florkowski and Schuster, 1992). While turnover is the behavior of employee to

${ }^{1}$ Ho Chi Minh City Open University.

${ }^{2}$ Deputy Director at Indovina Bank, Dong Nai Branch. 
withdraw or terminate his or her job with an organization, turnover intention is the attitude or an indication of an individual's readiness to quit his or her job. Turnover intention can be identified by its predictors with two groups: controllable and uncontrollable predictors. Controllable groups of predictors are such as job satisfaction, organizational commitment and organizational justice... The uncontrollable groups of predictors are perceived alternative employment opportunities, perceived ease of movement and demographic factors (Price and Mueller, 1986; Griffeth et al, 2000; Hom et al, 1992, 1995; Tett and Meyer, 1993).

Job satisfaction is simply the extent to which people like (satisfaction) or dislike (dissatisfaction) their jobs. Herzberg et al (1987) stated that satisfaction and dissatisfaction were driven by different factors - motivation and hygiene factors. Motivation factors are factors that make people want to work and provide satisfaction. Motivation factors are intrinsic and include achievement, recognition, promotion, growth, responsibility, and the work itself. Motivation factors help to increase in satisfaction but they have little effect on dissatisfaction. On the other hand, dissatisfaction is driven by hygiene factors. Extrinsic and hygiene factors include payment, job security, benefits, supervision, status, relationship with co-workers, physical environment, and company policies (Herzberg, 1987). These factors, if absent or inadequate, cause dissatisfaction. In range of affect theory, Locke (1976) was arguably the most famous job satisfaction model. This theory proposes that satisfaction with any job facet is determined by two factors: the have-want discrepancy for the facet and the importance of the facet. Further, the theory depicts how much a person values a given facet of work determines his or her level of satisfaction for a job facet. This theory allowed for the possibility to predict when employees would experience satisfaction or dissatisfaction in a particular job aspect. Facet satisfaction would be highest when the amount of satisfaction received was the same as the amount wanted by an individual for facets with high importance. Many research and models related to job satisfaction and motivation were conducted by the previous researchers. The core selfevaluations model, proposed by Judge, Locke and Durham in 1997, indicated that there were four core self-evaluations that determined one's disposition towards job satisfaction: self-esteem, locus of control, general self-efficacy and eroticism. In job characteristics model, Hackman and Oldham (1975) stated that there were five core job characteristics. These five core areas are skill variety, task identity, task significance, autonomy, and feedback. These five core areas impacted three critical psychological states. These included experienced meaningfulness, experienced responsibility for outcomes, and knowledge of the actual results. The result was the three critical psychological states impacting the work outcomes such as job satisfaction, absenteeism, and work motivation. Vroom's model was based on three concepts: valence, instrumentality, and expectancy. Valence is strength of an individual's preference for a particular outcome. Instrumentality is means of the first level outcome in obtaining the desired second level outcome. Expectancy is probability or the strength of belief that a particular action would lead to a particular first level outcome. Vroom (1964) believed that the product of these variables was the motivation.

Organizational commitment has become one of the most popular work attitudes studied by practitioners and researchers (Meyer, Allen \& Smith, 1993; 
Mowday, Porter \& Steers, 1982). These researchers had found that committed employees were more likely to remain with the organization and strived towards the organization's mission, goals and objectives. Organizational commitment was defined as the degree to which the employee felt devoted to their organization (Spector, 1997, 2000). There was general acceptance that organizational commitment had three main facets: affective, continuance and normative, each with its own underlying "psychological states" (Meyer \& Allen, 1985). Affective commitment was defined as the emotional attachment, identification, and involvement that an employee has with its organization and goals. Affective commitment can be characterized by three factors (1) "belief in and acceptance of the organization's goals and values, (2) a willingness to focus effort on helping the organization achieve its goal's, and (3) a desire to maintain organizational membership". Continuance commitment was the willingness to remain in an organization because of the investment that the employee has with "nontransferable" investments. Nontransferable investments include things such as retirement, relationships with other employees, or things that are special to the organization (Reichers, 1985). Continuance commitment also includes factors such as years of employment or benefits that the employee may receive that are unique to the organization (Reichers, 1985). Normative commitment (Bolon, 1993, 1997) is the commitment that people believes that they have to the organization or their feeling of obligation to their workplace. Weiner discusses normative commitment as being a "generalized value of loyalty and duty". It is "a feeling of obligation". It is argued that normative commitment is only natural due to the way we are raised in society. Normative commitment can be explained by other commitments such as marriage, family, religion, etc. therefore when it comes to one's commitment to their place of employment they often feel like they have a moral obligation to the organization (Weiner, 1982).

Organizational justice had witnessed an increasing amount of research. Organizational justice was a term used to describe farness in the workplace. It was concerned with the ways in which employees determined if they had been treated fairly in their jobs and the ways in which this determination influenced other work-related variables (Moorman, 1991.) There were two forms of organizational justice: distributive justice, which described the fairness of the outcomes an employee receives; and procedural justice, which described the fairness of the procedures used to determine those outcomes (Folger \& Greenberg, 1985.)

Based on literature review and models tested by previous researchers, this research proposed a research model as described in the figure below.

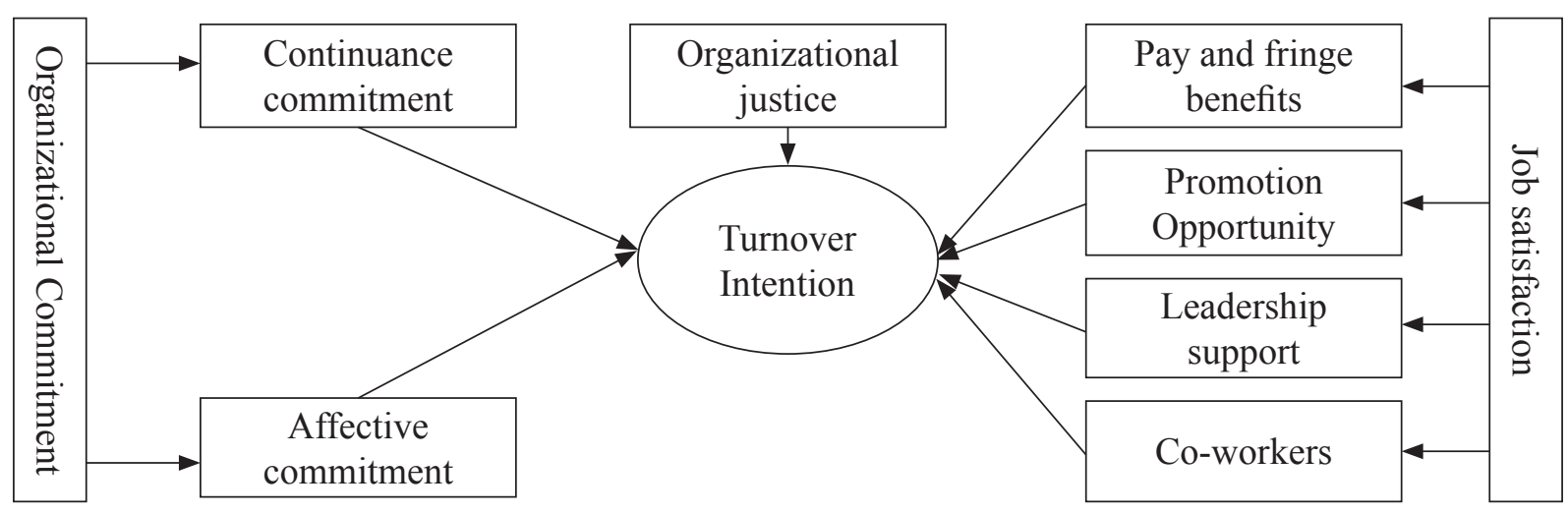




\section{RESEARCH METHODOLOGY}

The research has applied a combination of qualitative and quantitative research. After qualitative research, a proposed research model was formed with 7 factors comprised into three groups i.e. job satisfaction, organizational commitment, organizational justice. As indicated in the research model, these factors including pay and benefits, promotion, supervision, coworker, affective commitment, continuance commitment and organizational justice influence on employee's turnover intention.

In quantitative research, a survey was conducted with over 600 employees of Indovina Bank. Simple random sampling was used to send questionnaires to 342 employees. Finally, total 246 responds were received. Questionnaires with Likert 5 scale for measurement of the factors were used. Each factor was measured by 4 variables. Besides the descriptive statistic, Cronbach's alpha and EFA were used to test the reliability of measurement scale for each factor. Finally, multiple regression analysis was used to study the correlation and test the hypotheses.

Measurement scales and questionnaire sources in this research were adapted from Paul E Spector's famous Job Satisfaction Survey, from Dr Meyer and Allen's TCM of commitment. Table 1 shows how variables used in this research are defined and measured.

Table 1: Variables definition, and measurement and descriptive statistics of the research model

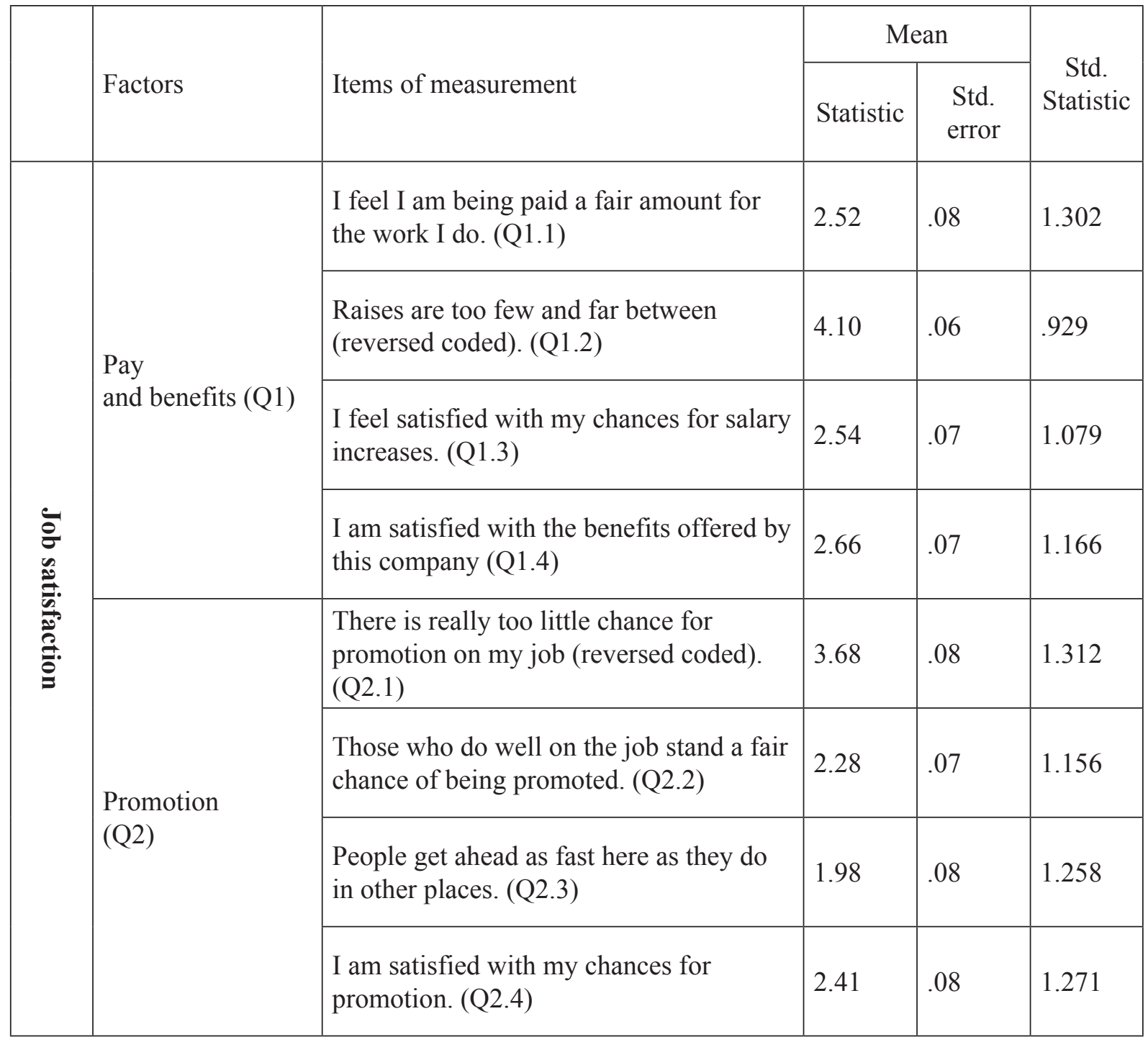




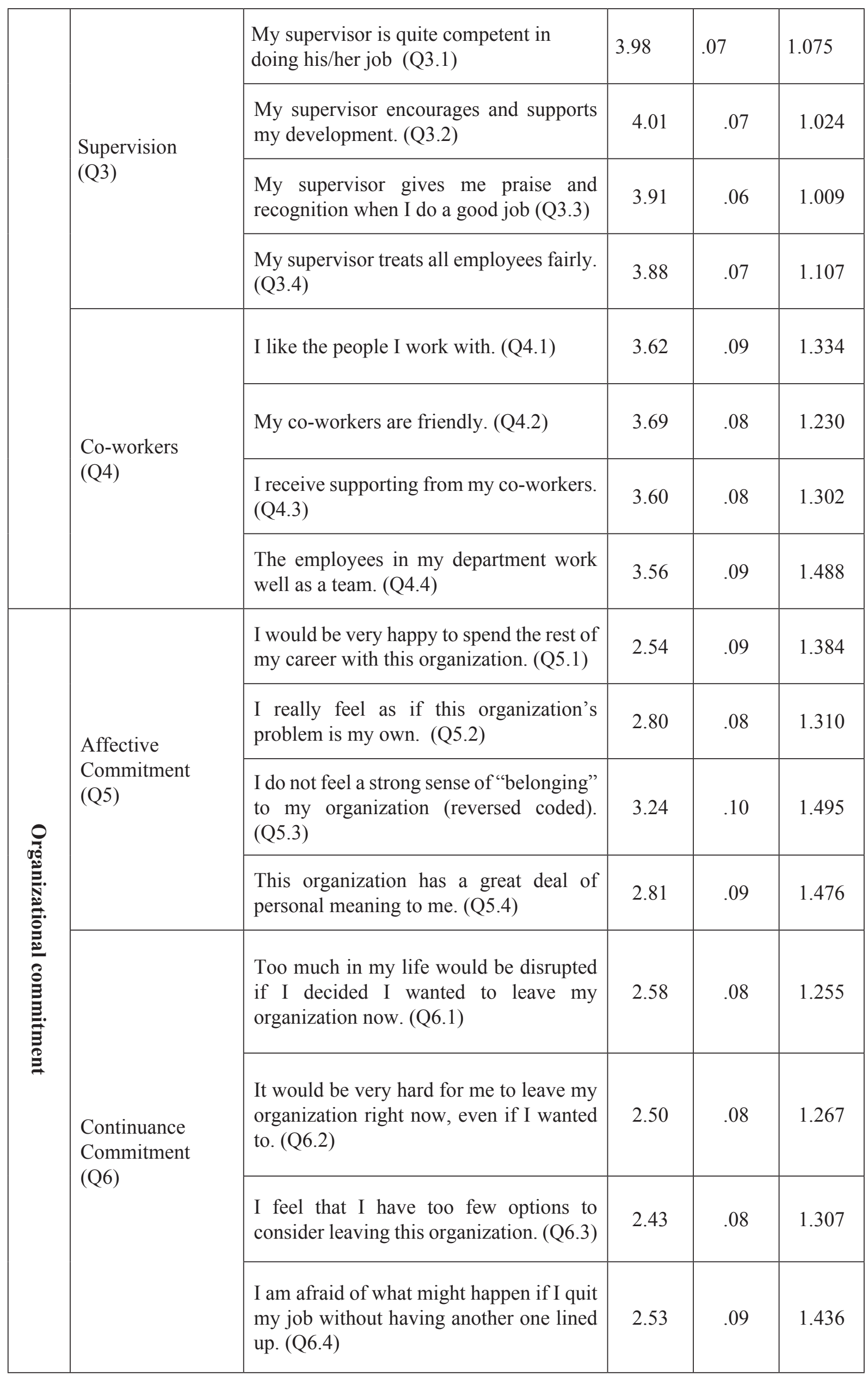




\begin{tabular}{|l|l|l|c|c|c|}
\hline & I consider the evaluation to be fair. & 3.11 & .07 & 1.149 \\
\cline { 2 - 6 } & $\begin{array}{l}\text { Organizational } \\
\text { Justice } \\
\text { (Q7) }\end{array}$ & $\begin{array}{l}\text { The evaluation reflected the quality of } \\
\text { my performance. (Q7.1) }\end{array}$ & 3.09 & .09 & 1.342 \\
\cline { 2 - 6 } & $\begin{array}{l}\text { I receive the fair evaluation with what I } \\
\text { have contributed. (Q7.2) }\end{array}$ & 3.17 & .09 & 1.349 \\
\cline { 2 - 6 } & $\begin{array}{l}\text { The rules, procedures, policies used to } \\
\text { evaluate my performance were equitable. } \\
\text { (Q7.3) }\end{array}$ & 2.87 & .09 & 1.367 \\
\hline $\begin{array}{l}\text { Intention to quit } \\
\text { (Y) }\end{array}$ & $\begin{array}{l}\text { Thoughts about quit my job cross my } \\
\text { mind. (Y1) }\end{array}$ & $\begin{array}{l}\text { I will likely look for a new job whenever } \\
\text { possible. (Y2) }\end{array}$ & 3.63 & 1.295 \\
\cline { 2 - 6 } & $\begin{array}{l}\text { I plan to look for a new job within the } \\
\text { next 12 months. (Y3) }\end{array}$ & 3.2 & 1.431 \\
\hline
\end{tabular}

\section{DATA ANALYSIS AND} FINDINGS

Data analysis was performed with descriptive statistics, reliability test and regression analysis.

In terms of descriptive statistics, we noted that the mean of independent variables wasere ranging from the lowest point of 1.98 to the highest point of 4.1. This had indicated that employees had very high different viewpoint on the factors affecting to their intention to leave. The big ranging of mean also indicated that the employees were very satisfied with some factors and very dissatisfied with others. Questions relating to dependent variables stood in the range of 3.69 to 3.2. The figure reflected that the employees really had the intention to leave. However, the situation was not so serious, as their "intention to leave" was just "cross their mind" instead of they would have a really "plan to look for a new job". Descriptive statistics also had shown that female employees in Indovina Bank were double the number of male employees. The majority of employees were under 35 years of age. The majority of employees had the monthly income from 5 to 10 million VND. All employees were graduate or post-graduate. Working tenure of employees wasere less than 5 years.

Reliability test is performed via the tool of Cronbach's alpha and exploratory factor analysis. The tests of Cronbach's alpha are satisfied for all the measurement scales. The EFA with Quartimax rotation was proven that 7 factors were extracted with Eigenvalue $>1$. In this analysis, cumulative $=71.98 \%$ had proven that 7 factors had explained $71.98 \%$ of the variance of data with KMO ratio of 0.874 and all the loading factors were above 0.5 . The test has shown that the factors were good for regression analysis.

The regression analysis has confirmed that among 7 factors, there are only 5 factors having the impact on the intention to leave i.e. pay \& fringe benefits, promotion, affective commitment, continuance commitment and organizational justice. The analysis has not enough evidence to confirm supervision and co-worker in association with turnover intention. 
Based on the regression result, we could verify the important level of the factors influencing on dependent variable. We noted that Affective commitment (Q5) was the most important factor, second was Salary \& benefits $(\mathrm{Q} 1)$, the third was Continuance commitment (Q6), next was Promotion (Q2)

Table 2. ANOVA(b)

\begin{tabular}{|c|l|l|l|l|l|l|}
\hline Model 1 & & Sum of Squares & df & Mean Square & F & Sig. \\
\cline { 1 - 5 } & Regression & 262.738 & 7 & 37.534 & 85.274 & $.000(\mathrm{a})$ \\
Residual & 104.757 & 238 & .440 & & \\
Total & 367.496 & 245 & & & \\
\hline
\end{tabular}

a Predictors: (Constant), Q7, Q3, Q4, Q2, Q1, Q6, Q5

b Dependent Variable: $Y$

Table 3. Coefficients and Levels of importance for the factors

\begin{tabular}{|c|c|c|c|c|c|}
\hline Variables & $\begin{array}{l}\text { Unstandardized } \\
\text { coefficient beta }\end{array}$ & $\begin{array}{l}\text { Standardized } \\
\text { coefficients } \\
\text { beta }\end{array}$ & Sig & $\begin{array}{c}\text { Level of } \\
\text { importance }\end{array}$ & Remark \\
\hline $\begin{array}{l}\text { Affective } \\
\text { commitment }\end{array}$ & -.393 & .054 & .000 & 1 & \\
\hline Pay \& benefits & -.282 & .062 & .000 & 2 & \\
\hline $\begin{array}{l}\text { Continuance } \\
\text { commitment }\end{array}$ & -.245 & .051 & .000 & 3 & \\
\hline Promotion & -.174 & .046 & .000 & 4 & \\
\hline Organizational justice & -.147 & .050 & .004 & 5 & \\
\hline Supervision & .064 & .049 & .193 & 6 & Not valid \\
\hline Co-worker & -.027 & .038 & .473 & 7 & Not valid \\
\hline Constant & 6.547 & & .000 & & \\
\hline
\end{tabular}

Affective commitment: the regression model had supported that affection commitment was the most important factor negatively associated with intention to leave. More employees agreed they had the intention to leave due to this factor. This was implied that in Indovina Bank's context, the affective commitment of employees was not high. As supported in literature, the fact also means that employees do not have strong beliefs in and acceptance of the organization's goals and values, they also do not have a willingness to exert considerable effort on behalf of the organization as well as a strong desire to maintain membership in the organization. In other words, the bank is weak in building this policy.

Pay \& benefits also negatively impacted to the turnover intention. To employees, total income is the most concern of job. They work to obtain basic needs 
for physical survival so that they can take care of their families. Incentive and fair pay may give workers the encouragement to stay in the organization and to enhance their contribution to the organization. Also, benefits are an effective tool used to motivate employees for reaching company goals and increasing loyalty as well as job satisfaction and commitment to the organization. Through the research, we knew that salary \& benefits of Indovina Bank were not satisfied by the employees.

Continuance commitment: the regression also confirmed that continuance commitment negatively impacted to turnover intention. The research revealed that employees in Indovina Bank also perceived continuance commitment as another important factor contributing to their intention to leave. It demonstrated that the bank did not pay much attention in "nontransferable" investments into their employees. These investments were including special benefit scheme based on years of employment, special retirement fund, the relationship with other employees, training expense tied to years of service....

Promotion: this factor was also considered as another important predictor to employees' turnover intention. It has proven that the employees of Indovina Bank are not satisfied with this matter. In an organization, if we could build a good promotion policy for employees, it would be a good motivation to make employees perform better as well as improve their skills and knowledge. Once employees were well motivated, they would be more devoted to the organization, and thus, the turnover problem was reduced.

Organizational justice: this was a very basic factor contributing to employees' intention to leave. Organizational justice had involved fair reward \& recognition system, fair evaluating system to access
employees...If employees perceived their performance to be evaluated fairly, and reward was allocated fairly, they would satisfy with their job and work harder for better development, thus they would be more committed to the organization and the turnover problem was improved. In Indovina Bank's context, in fact, the bank still did not build a comprehensive policy about performance rewards. Indovina Bank has still neglected to establish a management system and detailed criteria assessment of work, so that they can measure the level of fulfillment of workers, reward or penalty fairly or accurately.

Supervision: we could not find any evidence for the association between supervision and intention to leave. It also meant that employees of Indovina Bank were satisfied with this facet. This has proved that employees of Indovina Bank especially the middle level ones are quite competent and good in managing of their daily work. The treatment between staff level and managerial level is also good. Managerial level has paid more attention to the feeling and thinking of their subordinates.

Co-worker: We also could not find any evidence to confirm the association of this facet to the turnover intention. We can conclude that employees are satisfied with this facet. In fact, the level of competition between employees working in Indovina Bank was not so harsh. The employees were willing to cooperate and assist with each other in fulfillment of their tasks. The bank should further exploit this factor to make it become a good working culture for the bank.

\section{DISCUSSION AND RECOMMENDATIONS}

With the factors as described in the findings, this research confirmed that the majority of employees are satisfaction with supervision and co-workers and 
they are not satisfied with pay \& benefits and promotion. In short, the extent of employees' job satisfaction with IVB is at the average or above average level. The research has also explored that affective commitment and continuance commitment are very crucial factors to retain employees. However, IVB are not aware of this matter. Through the research, the management may have a better view of understandings on turnover and its antecedents especially the concept of and the importance of affective commitment and continuance commitment, so that they will pay more attention to these factors in the future.

The recommendations shall be made to improve the human resource practices of IVB and in connection with the factors analyzed from the research model. There are total 9 recommendations based on 5 factors explored by the research. The recommendations can be divided into 3 groups which will improve organizational commitment, job satisfaction and organizational justice.

In improving organizational commitment, Indovina Bank should firstly build the bank's vision and mission. If the bank could have its mission and vision widely circulated and broadcasted to all its employees, it will have a lot of benefits. Employees will understand clearly the organization's goal and share with its effort to achieve this and each individual's goal shall be performed on an axis of organization's goal. Secondly, the bank also should build its organization's culture to act as a glue to hold employees with their organization. The organization culture can be cultivated by tapping into the first level artifacts. With IVB, it can choose an icon for the bank for example a kind of flower as a corporate flower and create a corporate song. These things can be introduced in company's profile together with its mission and vision.
Organize ceremonies such as Corporate birthday, staff family day... and invite all the employees to actively participate in these involvements. Thirdly, the management may also consider in building non-transferable investment scheme. These investments are for the purpose to retain employees and also improving the working tenure. These things can be considered as retirement fund or benefits or allowance due to years of service with the organization, or something special and unique to that organization. With these investment funds, the employees shall be tied to their organization in terms of economic. They have to loose a sum of money or benefits if they decide to quit their job.

In improving job satisfaction, firstly, the Management should periodically review the salary policy. IVB should do periodical surveys among other banks to obtain and update information about the remuneration standards. It is agreeable that the raise of basic salary will certainly cause more cost for the bank, however, in the view that labor force is a valuable asset, the adjusting of the salary level to be more updated to the industry standards is necessary. Secondly, Indovina Bank should do more investment on benefit policy such as medical insurance, house allowance, paid holidays... The current benefit of IVB granted to the majority of employees is only meal allowance and selective travel allowance provided for employees working out of the province. Thirdly, quickly establish a training centre in HO. The bank should build a professional training not only for training new staffs but also for the improvement of skills and competence for other level of staffs. At that time, the work forces of IVB are always ready and easier for promotion. Lastly, extend the career development purpose in appraisal system. The performance appraisal system 
of IVB is very simple and it has only one purpose i.e. to serve as a tool for giving bonus to employees (please refer to item 1.3.4 in appendix A for more information.) The bank has neglected another important purpose of the appraisal system i.e. career development. A comprehensive appraisal system must cover at least three purposes such as administration usage, career development and feedback. With a good career development program and policy, the employees will be able to satisfy a higher level of their need such as esteem and achievement, they will be more devoted to the organization.

In improving organizational justice, first thing that the bank may do is to revise the policy and procedures in evaluation of staff performance. This is also another matter belonging to the weakness in the appraisal system of Indovina Bank. The bank should not implement the regulation of quota in staff performance appraisal (please refer to item 1.3.4 in appendix A for more information.) With the quota, the employees will have the feelings that they are not evaluated fairly and the evaluation also does not reflect their true performance. The bank can consider in converting grade A, B, C, D to point. For example from point 85 to 100 is excellent, from 75 to 84 is good, from 50 to 74 is average ... For this new rating, it will be more accurate and objective in staff evaluation. Later, the bank can consider in revising the bonus payment system. It is understood that the quota in bonus scheme is unavoidable. However, it is able to create a new form of calculating to solve this conflict. For example, the bank will not announce that grade A or grade B will have exactly how much bonus, instead, the bonus is calculated in point. With this new method, the quota is implied into the system, but it still does not affect the performance appraisal.

\section{REFERENCES}

1. Bolon, D.S. (1997), “Organizational Citizenship Behavior Among Hospital Employees: A Multidimensional Analysis Involving job Satisfaction and Organizational Commitment", Hospital \& Health Services Administration, 42, 2 , 221-241.

2. Florkowski, G \& Schuster, M. (1992), "Support for profit sharing and organizational commitment: A path analysis". Human Relations, 45, 5, 507-523.

3. Folger, R. and Greenberg, J. (1985), "Procedural justice: An interpretative analysis of personnel systems", Research in Personnel and Human Resources Management, 3: $141-183$.

4. Griffeth, R.W. (2000), Employee turnover, Cincinnati: South-Western.

5. Hackman, J.R. \& Oldham, G.R. (1975), "Development of the job diagnostic survey”, Journal of Applied Psychology, 60(2), 159-170.

6. Herzberg, Frederick, Dora Capweii, Bernard Mausner, and Richard Peterson, Job Attitudes, New York Garland Riblishing Inc., 1987.

7. Hom, P.W. \& Griffeth, R.W. (1995), Employee turnover, Cincinnati: South-Western.

8. Kowlowsky, M. (1987), "Antecedents and consequences of turnover: An integrated systems approach", Genetic, Social and General Psychology Monographs, 113 (3), 269-292. 
9. Lee. T.W. \& Mowday, R.T. (1987), "Voluntarily leaving an organization: An empirical investigation of Steers and Mowday's model of turnover", Academy of Management Journal, 30, 721-743.

10. Locke, E.A. (1976), "The nature and causes of job satisfaction. In M.D. Dunnette (Ed.)",Handbook of industrial and organizational psychology (pp. 1297-1349). Chicago: Rand McNally.

11. Meyer, J.P. \& Allen, N.J. (1993), A Three-component conceptualization of organizational commitment, Human Resource Management Review, 1, 61-89.

12. Meyer, J.P. \& Allen, N.J. (1985). Commitment in the Workplace: Theory, Research, and Application, Thousand Oaks, CA: Sage Publications.

13. Moorman, R.H. (1991), "Relationship between organizational justice and behavior: Do fairness perceptions influence employee citizenship", Journal of Applied Psychology, 76(5): 845-855.

14. Porter, L.W. \& Steers, R.M. (1982), “Organizational, work, and personal factors in employee turnover and absenteeism”, Psychological Bulletin, 80(2), 151-176.

15. Price, J.L. \& Meuller, C.W. (1981), "A causal model of turnover for nurses", Academy of Management Journal, 24(3), 543-565.

16. Price, J.L. \& Meuller, C.W.(1986), Absenteeism and turnover of hospital employees, Greenwich: JAI.

17. Reichers, Arnon (1985), "A review and reconceptualization of organizational commitment", The Academy of Management Review, 10, 3, 465-476.

18. Spector P, E (1997), Job satisfaction: Application, Assessment, Causes and Consequences, Sage Publication, International Educational \& Professional Publisher, London.

19. Tett, R. P., \& Meyer, J. P. (1993), ’Job satisfaction, organizational commitment, turnover intention, and turnover: Path analysis based on meta-analytic findings". Personnel Psychology, 46(2), 342-346.

20. Vroom, V. H. (1964), Work and motivation, Malabar, Florida: Robert E. Krieger Publishing Company.

21. Weiner, Y. (1982), "Commitment in Organization: A Normative View”, Academy of Management Review, 7, 418-428. 